\title{
Peripheral Giant Cell Granuloma-A Rare Oral Entity
}

\author{
Karthikeyan Ramalingam*, Sandeep Goyal and Sathya Sethuraman \\ Department of Oral Pathology and Microbiology, Surendera Dental College and Research Institute, Rajasthan, India
}

Submission: October 26, 2016; Published: December 04, 2017

*Corresponding author: Karthikeyan Ramalingam, Department of Oral Pathology and Microbiology, Surendera Dental College and Research Institute, Rajasthan, India, Email: drrkn79@gmail.com

\section{Abstract}

Peripheral Giant Cell granuloma (PGCG) is one of the hyperplastic lesions of the oral cavity. It could arise from the periosteum or the periodontal membrane subsequent to chronic trauma or local irritation. It accounts for less than $10 \%$ of all hyperplastic gingival lesions, rarely exceeds $2 \mathrm{~cm}$ in size and predominantly noted in females. We report a rare case of a large PGCG involving the right mandibular anterior gingiva in a 26-year-old male patient of Indian origin. It presented as a pinkish-red nodule which showed multinucleated giant cells in fibrous cellular stroma along with extravasated RBCs in histopathology. The lesion was surgically excised and the patient is remaining disease free on follow-up.

Keywords: Peripheral giant cell granuloma; Mandibular gingival; Males; Anterior region

Key Messages: We report the case of peripheral giant cell granuloma in the mandibular anterior gingiva in a male patient. This rare entity should be kept in mind on encountering such hyperplastic lesions in the oral cavity.

\section{Introduction}

Peripheral giant cell granuloma (PGCG) is the infrequent, exophytic oral lesion that commonly contains giant cells. It is also called as Giant Cell Epulis, Osteoclastoma, Giant cell reparative granuloma or giant cell hyperplasian [1,2]. It is a benign, generally asymptomatic, hyperplastic lesion arising from the attached gingiva or alveolar mucosa. It rarely presents as a mass greater than $1.5 \mathrm{~cm}$ in diameter [1].

It is not a true neoplasm but a benign, hyperplastic reaction to local irritation such as plaque, calculus, food impaction, ill-fitting dentures, poor dental restorations, chronic trauma and tooth extraction. The lesion depicts a chronic process with exaggerated repair of granulation tissue and scar formation following injury [3].

It is seen exclusively on the gingiva as a sessile or pedunculated mass. It could be a firm and smooth mass with regular outline or a multi-lobulated growth of irregular shape and surface indentations and with occasional ulcerated surface [1,3]. Its colour can vary from dark red to purple to blue and it is located in the interdental papilla, edentulous alveolar margin or at the marginal gingival level [3].

It is more common in females and in the mandible with a relative predilection of 40-60 years of age. Histopathology presents a highly cellular connective stroma with numerous multinucleated giant cells along with hemosiderin deposits and inflammatory cells [1].

We report a rare presentation of a large exophytic presentation of PGCG in the mandibular anterior gingiva of an26-year-old Indian male patient.

\section{Case History}

A 26-year-old male patient reported with a complaint of swelling in the front region of his lower jaw in the last 5 months. History revealed that it initiated as a small swelling and progressively increased in size over the period of the past five months. He had intermittent discomfort. There was no associated history of traumatic injury, rise in temperature, appetite loss, weight loss or neurological deficits. He did not have any other similar swelling in his body and was apparently health without any systemic diseases.

Inspection of the intra-oral swelling revealed a nodulated pinkish-red swelling in the mandibular gingiva extending from mesial surface of 41 till the mesial surface of 44 . It was around $2.5 \mathrm{~cm} \times 1.7 \mathrm{~cm}$ in size. Palpation revealed a firm consistency and slight bleeding. The overlying mucosa was slightly ulcerated (Figure 1). There was local accumulation of plaque and calculus on Investigations including intra-oral periapical radiographs, orthopantomogram and occlusal radiographs did not reveal any bone resorption. 

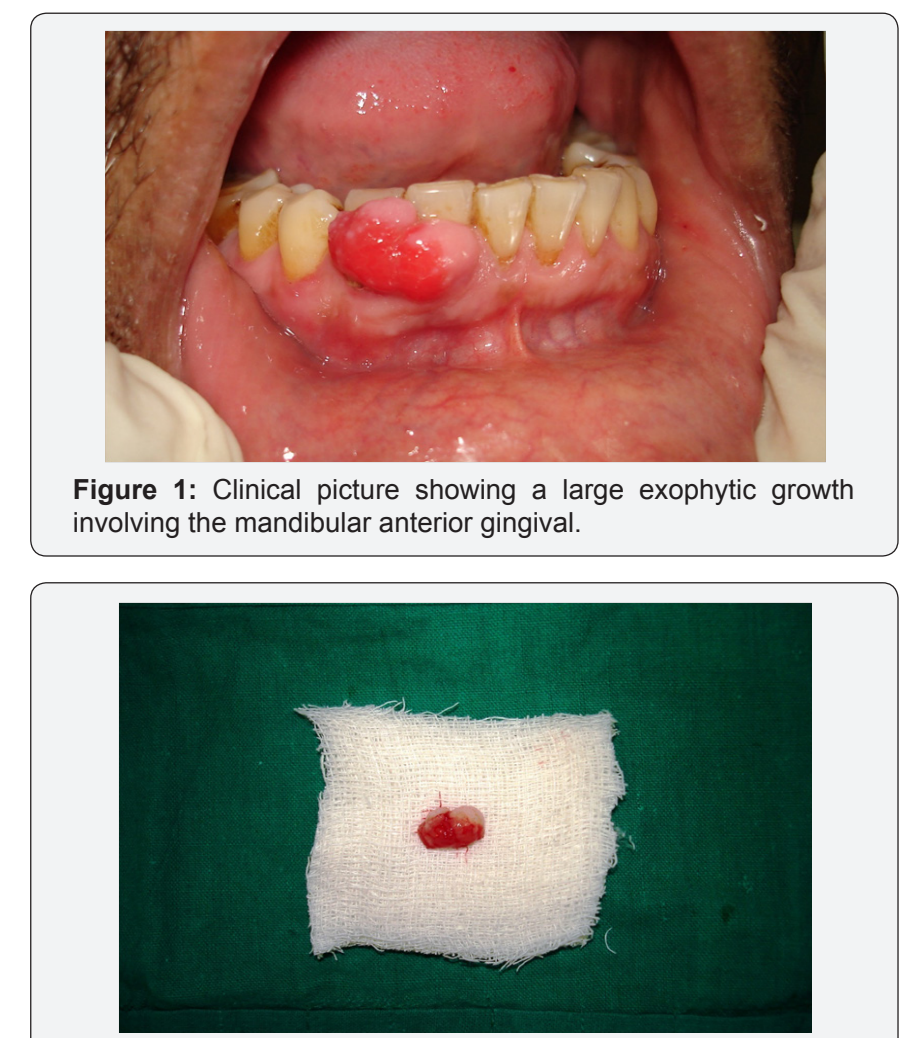

Figure 2: Picture showing the post-surgical excised tissue sample.

The lesion was surgically excised under local anaesthesia (Figure 2) and the excisional biopsy was submitted to Department of Oral Pathology and Microbiology, Surendera Dental College and Research Institute for histopathological examination.

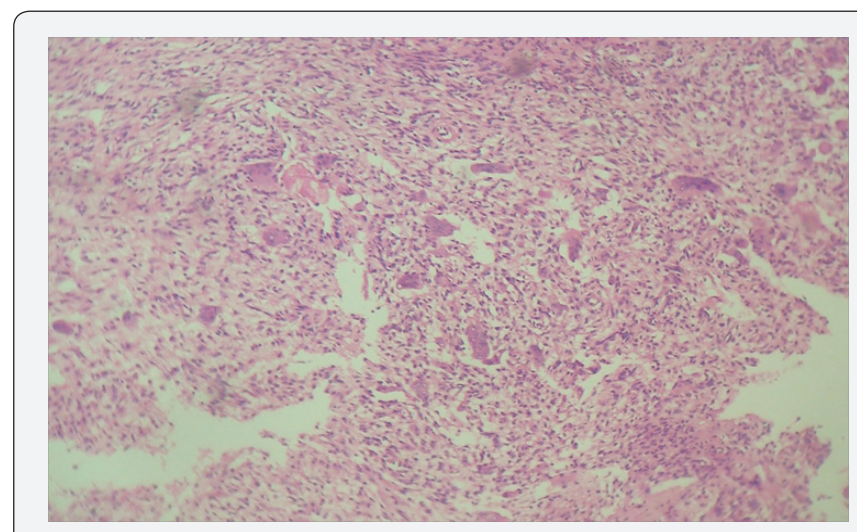

Figure 3: Photomicrograph of $\mathrm{H} \& \mathrm{E}$ stained section with numerous giant cells in a connective tissue stroma along with chronic inflammatory cells. (10x magnification).

Gross examination of the tissue sample revealed a whitishbrown mass that was firm in consistency. Histopathologies revealed H\&E stained section with fibrous cellular connective tissue stroma intermixed with numerous multinucleated giant cells and diffuse chronic inflammatory cell infiltrate (Figure $3)$. The giant cells were dispersed uniformly throughout the lesion, contained12-20 large, vesicular nuclei in an eosinophilic cytoplasm (Figure 4). There was evidence of hemosiderin deposits, dilated capillaries and extravasated RBCs in the connective tissue stroma (Figure 5). Correlating the clinical, radiological and histopathological features, the lesion was diagnosed as Peripheral Giant Cell Granuloma(PGCG). The patient is remaining diseasefree on follow-up without any recurrence.

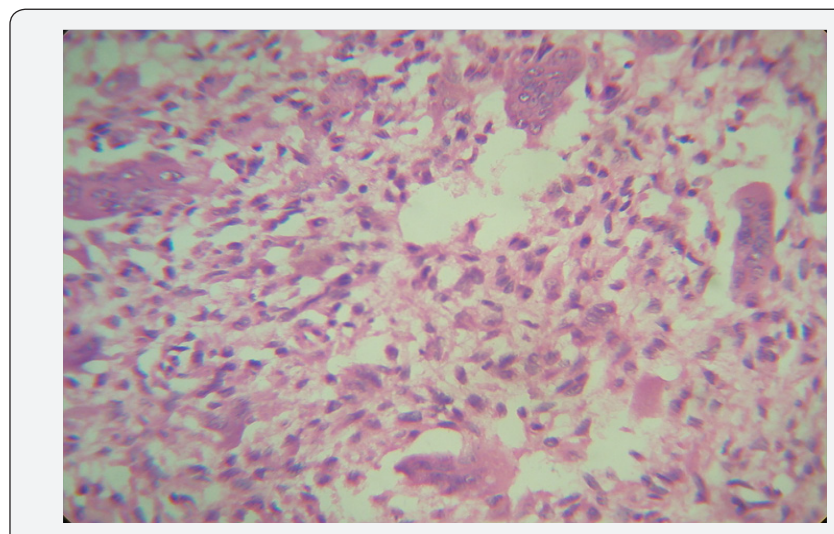

Figure 4: Photomicrograph of $\mathrm{H} \& \mathrm{E}$ stained section showing multinucleated giant cells with large, vesicular nuclei in eosinophilic cytoplasm (40 x magnifications).

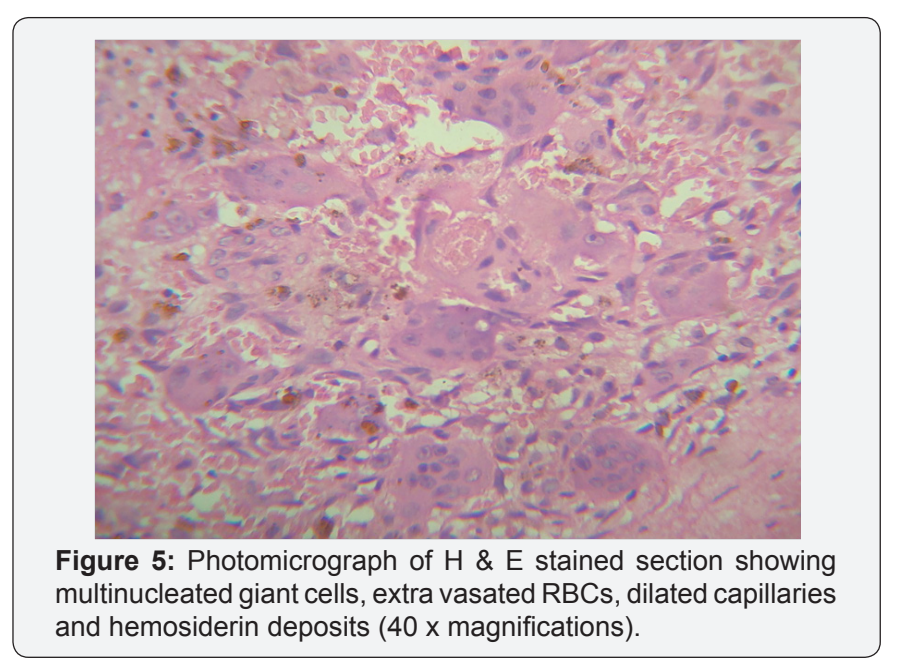

\section{Discussion}

The etiology and nature of PGCG is still unclear. It was hypothesized that these multinucleated giant cells are osteoclasts left after physiological tooth resorption or periosteal injury. These giant cells showed calcitonin receptors and also exhibited in-vitro resorption [2].

PGCG accounts for less than $10 \%$ of all hyperplastic gingival lesions and $94 \%$ of these lesions are less than $1.5 \mathrm{~cm}$ in size and rarely exceed $2 \mathrm{~cm}$ in diameter[1,3] Our presentation was larger than the normal range and required careful surgical excision.

PGCG can be sessile or pedunculated mass spreading through penetration of periodontal membrane [1]. Literature reported the average age of incidence is 30-33 years, female predominance of 2: 1 or 1.5:1 than males [3]. We report a rare presentation of PGCG in a 26-year-old male patient.

PGCG is more common in lower jaw and frequently involving premolar-molar region [3]. Shafer and Waldron suggested that 
it generally occurs in the incisor and canine region [1]. Our case presented as a large exophytic mass in the mandibular anterior gingiva involving the incisor and canine region.

The consistency of the lesion depends on the age of the lesion. The increase in collagen fibres with time leads to a shift in consistency from soft to firm in nature [3]. Our presentation was firm in consistency due to its longer duration.

It has been reported that PGCG can be associated with mobility and displacement of involved teeth. They are painless, if they do not interfere with occlusion [1]. It was not present in our case. There is no pathognomonic clinical feature to distinguish PGCG from other gingival enlargements like Pyogenic granuloma, peripheral ossifying fibroma and peripheral cemento-ossifying fibroma. There is an overlap of clinical and radiological features among these lesions [1].

Histopathology shows excess number of giant cells distributed throughout the connective tissue stroma. The origin of giant cells is still unknown but they are proposed to originate from osteoblasts, phagocytes, endothelial cells and spindle cells. They could also arise from giant cells associated with resorption of deciduous teeth. Immunohistochemical analysis revealed that they arise from mononuclear phagocyte system. Histopathological assessment is mandatory for definitive diagnosis [1]. Giant cells may show few to several dozen nuclei which may be large and vesicular or small and pyknotic in nature [2]. Our case showed numerous giant cells with 15-20 large, vesicular nuclei. There were evidence of hemosiderin deposits and chronic inflammation dispersed in the connective tissue stroma.
It is critical to differentiate PGCG from its central variant. Central giant cell granuloma is situated within the jaw bones, displays more aggressive behaviour and could be differentiated only by radiological investigations [1]. Extra-osseous lesions of cherubism also show giant cell lesions but can be ruled out by its clinical and radiological features [2]. Our case did not have any bone involvement which confirmed the peripheral nature.

Treatment of PGCG includes surgical excision with the base of the lesion along with elimination of the etiological factors. Superficial resection can lead to recurrence. Most lesions respond favourably to complete surgical resection with exposure of bone walls [3]. Complete surgical excision was performed in our case and he is remaining disease free on follow-up.

\section{Conclusion}

Early diagnosis of PGCG leads to a conservative surgical excision that has long term benefits, as there is reduced chance of tooth or bone loss. We recommend the inclusion of PGCG in the differential diagnosis of exophytic lesions in the gingiva in such rare clinical presentations.

\section{References}

1. Rodrigues SV, Mitra DK, Pawar SD, Vijayakar HN (2015) Peripheral Giant Cell granuloma: This enormity is a rarity. J Indian SocPeriodontol 19(4): 466-469.

2. Tandon PN, Gupta SK, Gupta DS, Jurel SK, Saraswat A (2012) Peripheral giant cell granuloma. ContempClin Dent 3(Suppl1): 118-121.

3. Shadman N, Ebrahimi SF, Jafari S, Eslami M (2009) Peripheral Giant Cell Granuloma: A Review of 123 Cases Dent Res J (Isfahan) 6(1): 47-50.

\section{Your next submission with Juniper Publishers will reach you the below assets}

- Quality Editorial service

- Swift Peer Review

- Reprints availability

- E-prints Service

- Manuscript Podcast for convenient understanding

- Global attainment for your research

- Manuscript accessibility in different formats

(Pdf, E-pub, Full Text, Audio)

- Unceasing customer service

Track the below URL for one-step submission https://juniperpublishers.com/online-submission.php 